\title{
MSK1 promotes cell proliferation and metastasis in uveal melanoma by phosphorylating CREB
}

\author{
Jianchang Li, Xiuming Liu, Wenqi Wang, Chaopeng Li, Xiaofeng Li
}

Department of Ophthalmology, The Affiliated Huaian No. 1 People's Hospital of Nanjing Medical University, Huai' an, Jiangsu, China

Submitted: 4 December 2018

Accepted: 23 April 2019

Arch Med Sci 2020; 16 (5): 1176-1188

DOI: https://doi.org/10.5114/aoms.2019.85810

Copyright $\odot 2019$ Termedia \& Banach

\section{Abstract}

Introduction: Uveal melanoma is known as a frequent intraocular tumor, with high metastasis and poor prognosis. Mitogen- and stress-activated protein kinase 1 (MSK1) is a serine/threonine kinase that has been reported to be associated with tumor progression in several types of human cancer. However, the role of MSK1 has rarely been studied in uveal melanoma and the underlying mechanism remained unclear.

Material and methods: The expression level of MSK1 in human uveal melanoma tissues and normal uveal tissues was determined by qRT-PCR analysis, western blotting and immunohistochemistry (IHC). Subsequently, MTT assay, colony formation assay and flow cytometry assay were performed to assess the effects of MSK1 on cell proliferation. Wound-healing and transwell chamber assays were adopted to clarify the role of MSK 1 in cell metastasis. Finally, the function of MSK1 was confirmed in vivo in a tumor-bearing mouse model.

Results: The expression levels of MSK1 and p-cyclic AMP-responsive element binding protein (CREB) were strongly up-regulated in human uveal melanoma tissues. MSK1 overexpression facilitated cell viability and clone formation, and promoted migration and invasion of uveal melanoma cells. However, mutation of cyclic AMP-responsive element binding protein (CREB) at Ser133 residues reversed the effect of MSK1 on uveal melanoma cell proliferation and metastasis. The in vivo experiment suggested that the tumor weight was lower and the tumor mass grew more slowly in the shMSK1 group as compared to the shNC group.

Conclusions: MSK1 promotes proliferation and metastasis of uveal melanoma cells by phosphorylated CREB at Ser133 residues. Therefore, MSK1 could be a promising candidate for uveal melanoma therapy and especially has tremendous potential in the treatment of cancers in which the MSK1-CREB pathway is abnormally active.

Key words: mitogen- and stress-activated protein kinase 1, uveal melanoma, p-cyclic AMP-responsive element binding protein, proliferation, metastasis, phosphorylation.

\section{Introduction}

Uveal melanoma, originating from melanocyte malignant transformation, is known as a frequent intraocular tumor with high metastasis and poor prognosis and is usually found in people living into old age [1, 2]. Patients diagnosed with liver metastasis usually died within several months, and the high mortality of uveal melanoma patients was main-

\author{
Corresponding author: \\ Jianchang Li \\ Department \\ of Ophthalmology \\ The Affiliated Huai'an \\ No. 1 People's Hospital \\ of Nanjing Medical \\ University \\ Huanghe Road West \\ Huai'an City \\ Huaiyin District \\ Huai'an, Jiangsu \\ 223300, China \\ Phone: +86 0517-80872120 \\ Fax: +86 0517-80872120 \\ E-mail: \\ Lijianchang5454@163.com
}


ly due to hepatic metastasis via hematogenous spread $[3,4]$. There are miscellaneous treatments available for uveal melanoma by local treatment of the eyeball, including surgical resection of diseased eyeball, radioactive plaque therapy, proton beam radiotherapy, transpupillary thermotherapy and chemotherapy, which had no significant improvement in metastatic and prognosis for patients [5-7]. The 5-year survival rate remained poor especially at the disseminated stage in past decades, which is attributed to the lack of effective therapy for metastasis $[8,9]$. Therefore, there is a demand to illuminate the underlying metastatic mechanisms of uveal melanoma and to develop more efficient modalities against primary and metastatic uveal melanoma to improve survival of uveal melanoma patients.

Mitogen- and stress-activated protein kinase 1 (MSK1), also called as RPS6KA5, was first identified in 1998 as a protein, and proved to be a serine/ threonine kinase that shared homology to the RSK kinase family (ribosomal protein-S6 kinase) [1012]. Importantly, MSK1 is ubiquitously expressed in multiple tissues such as brain, heart, placenta, and skeletal muscles, whose level is high in immune and neuronal cells $[13,14]$. Previous studies have shown that MSK1 is activated by estrogens or progestins and is required for breast cancer cell proliferation, whereas Xuan Pu et al. reported that high nuclear MSK1 favored longer survival in breast cancer patients $[15,16]$. MSK1 knockdown inhibited anchorage-independent growth of $\mathrm{Ci}$ ras-3 cells and improved their malignant phenotype [17]. Overexpression of MSK1 triggered tumor invasion and poor prognosis in colorectal cancer [18]. Furthermore, MSK1 was implicated in gastric cancer [19] and skin tumor development [20]. These studies suggest that MSK1 plays a crucial role in tumor progression via regulating cancer cell proliferation and metastasis. However, the role of MSK1 has rarely been studied in uveal melanoma and the mechanism also remained unclear.

MSK1 is a nuclear protein activated by the ERK $1 / 2$ or p38 MAPK pathway which was stimulated by growth factor and cellular stress stimuli $[21,22]$. Activated MSK1 phosphorylates various downstream genes including cyclic AMP-responsive element binding protein (CREB) via phosphorylating it at Ser133 [23, 24]. MSK1 has been shown to be essential for CREB phosphorylation due to mitogen stimulation in mouse embryonic stem cells [25]. The p38/MSK1/CREB/MITF axis was involved in melanogenesis in human melanocytes stimulated by the stem cell factor [26]. Cytokine production in human neutrophils was modulated through the p38-MSK1-CREB signaling cascade [27]. TNF activates CREB by phosphorylation on serine 133 via the p38 MAPK/MSK1 axis in endothelial cells [28]. These studies indicate the important role of MSK1 in regulating tumor progression through promoting CREB phosphorylation at Ser133 site.

Here, we are intended to investigate the potential role of MSK1 in uveal melanoma. Up-regulated MSK1 was observed in human uveal melanoma tissues compared with normal uveal tissues. MSK1 promotes proliferation and metastasis of uveal melanoma cells. Finally, we clarified the potential underlying mechanism that is strongly associated with the phosphorylation of CREB at Ser133 residues via the MSK1/CREB signaling pathway. The in vivo experiment indicated that inhibition of MSK1 suppressed tumor growth. All considered, MSK 1 could be a promising candidate for uveal melanoma therapy.

\section{Material and methods}

\section{Tissue samples}

Thirty patients who were exactly identified with primary uveal melanomas were used in this study. All tumor tissues were operated on enucleation and tissues without local therapy. Tissue samples were collected from the Affiliated Huaian No. 1 People's Hospital of Nanjing Medical University and approved by the Institutional Research Committee. Clinical features for each patient were recorded. The samples were then used for $q P C R$ and western blotting assays.

\section{Cell culture}

Human uveal melanoma cell lines OCM-1A and MUM-2C were obtained from the Center for Type Culture Collection of China. Cells were cultured in Roswell Park Memorial Institute (RPMI)1640 medium supplemented with $10 \%$ fetal bovine serum (FBS; HyClone, Grand Island, NY, USA) and penicillin/streptomycin (Sangon, Shanghai, China) at $37^{\circ} \mathrm{C}$ in a $5 \% \mathrm{CO}_{2}$ incubator. The cell samples were then collected and used for in vitro experiments.

\section{Plasmids' construction and transient transfection}

A double-stranded oligonucleotide corresponding to the human MSK1 sequence (5'- ATTTCCAAACAAGTCATAGGT-3) was synthesized and cloned into the $\mathrm{pBS} / \mathrm{U} 6$ vector (Addgene, Cambridge, MA, USA). The plasmid was then used to construct the short hairpin RNA (shRNA) for MSK1 downregulation. Meanwhile, pcDNA 3.1 vector (Addgene) was used for construction of the MSK1 expression plasmid. In addition, the human CREB sequence was cloned into the PCDNA 3.1 vector and then the construct $\mathrm{CREB}^{\mathrm{ser} 133}$ by site-directed mutagen- 
esis. Transient transfection was performed with Lipofectamine 2000 Transfection Reagent (Invitrogen, Carlsbad, CA, USA) as protocols.

\section{Real-time polymerase chain reaction (qPCR)}

RNA extraction of tissue samples and cells was performed using TRIzol Reagent (Invitrogen). $2 \mu \mathrm{g}$ of RNA was reverse-transcribed into cDNA and the M-MLV Reverse Transcriptase was used (Invitrogen). Real-time PCR was conducted on a CFX96 Real-Time PCR system (Bio-Rad, Hercules, CA, USA). Primers of MSK 1 used for amplification were as follows: 5'-CTGGTGGAGTTTGGGTGTTCT-3' (forward) and 5'-CTCCTGTAGGCAGACAAAACT-3' (reverse).

\section{Western blotting}

Total protein of $50 \mu \mathrm{g}$ was separated on $12 \%$ SDS-polyacrylamide gels and transferred to PVDF membranes, and the membrane was blocked with $5 \%$ nonfat milk in Tris-buffered saline (TBS), then incubated with the indicated primary antibodies. Antibodies against MSK1, CREB, pCREB, cyclin B1, cyclin D1, MMP2, MMP9, Fos, Jun and $\beta$-actin were obtained from Cell Signaling Technology (Beverly, MA, USA). Secondary antibodies were detected and quantified by ImageJ software (ImageJ version $1.44 p, N I H, M D, U S A)$.

\section{MTT assay}

Cell viability was analyzed by MTT assay. OCM$1 \mathrm{~A}$ and MUM-2C cells were seeded onto 96-well plates at a density of $5 \times 10^{3}$ cells/well. $10 \mu \mathrm{l}$ of 3-(4,5-dimethylthiazol-2-yl)-2,5-diphenyl-tetrazoliumbromide (MTT, $5 \mathrm{mg} / \mathrm{ml}$ ) was added into each well. Cells were then incubated for another $4 \mathrm{~h}$ at $37^{\circ} \mathrm{C}$. The medium was removed and $100 \mu \mathrm{l}$ of dimethyl sulfoxide (DMSO) was added to each well to resuspend the mitochondrial succinate mediated MTT formazan production. The absorbance of the dissolved formazan was measured at $490 \mathrm{~nm}$ with a scanning microplate spectrophotometer. For accuracy and reproducibility, all experimental sets were performed in triplicate and expressed as mean \pm SD.

\section{Soft agar colony formation assay}

For the colony formation assay, OCM-1A and MUM-2C cells were plated onto $10 \mathrm{~cm}$ dishes at a density of $5 \times 10^{4}$ cells per dish. Colonies composed of $>50$ cells were counted 10-14 days after seeding under the microscope (40x). The colonies were then stained for $30 \mathrm{~min} .0 .5 \%$ crystal violet in $20 \%$ methanol was used for staining and photographed. All experiments were performed in triplicate wells three times.

\section{Cell cycle analysis}

Flow cytometry was used to determine cell cycle stage. Cell samples were processed with the DNA-PREP Reagents Kit (Beckman-Coulter, Fullerton, CA, USA) according to the manufacturer's instructions and then transferred to an EPICS ALTRA flow cytometer (Beckman-Coulter). The cytometry data were analyzed with Multicycle software (Phoenix Flow Systems, San Diego, CA, USA).

\section{Wound-healing assay}

Cells were seeded onto $35 \mathrm{~mm}$ dishes and a uniform scratch was made using a $10 \mu \mathrm{l}$ pipette tip. The cells were then incubated for $48 \mathrm{~h}$ in a minimum medium. The speed of wound closure at intervals indicated cell motility and images were taken after the scratch was applied.

\section{Cell invasion assays}

The transwell chambers were solidified with Matrigel (BD Biosciences, San Jose, CA, USA) by incubation at $37^{\circ} \mathrm{C}$ for 6 h. $4 \times 10^{5}$ cells were added into the upper chamber in serum-free RPMI-1640 medium. Meanwhile, medium containing 10\% FBS was put in the lower chamber. After $24 \mathrm{~h}$, invasive cells on the lower chamber were stained and counted.

\section{Immunohistochemistry (IHC)}

Immunostaining of MSK1, pCREB and Ki67 was performed as described before [29]. Sections were incubated with MSK1 antibody (1 : 100, SAB4503597, Sigma-Aldrich, St. Louis, MO, USA), pCREB antibody (1 : 100, SAB4504375, Sigma-Aldrich) and Ki67 antibody (1 : 400, \#12202, Cell Signaling Technology). Horseradish peroxidase (HRP)-conjugated goat anti-rabbit IgG (1 : 1000, Antibodies-online, Aachen, Germany) was then added and incubated for $1 \mathrm{~h}$ at room temperature. Chromogenic reaction was performed by adding 3,3'-diaminobenzidine (DAB) (Solarbio, Beijing, China) and counterstaining with hematoxylin for better visualization.

\section{Mouse model}

We administered $3 \times 10^{6}$ OCM-1A cells of shcontrol or MSK1-shRNA in $100 \mu \mathrm{l}$ of PBS. Cells were subcutaneously injected into the right groin of female BALB/c nude mice (Beijing Vital River Laboratory Animal Technology Company, China). Tumor volume was calculated on every second day using the equation volume $\left(\mathrm{mm}^{3}\right)=\left(\right.$ length $\times$ width $\left.{ }^{2}\right) / 2$. The mice were then euthanized on post-injection day 14. Tumor masses were weighed and then subjected to western blotting analysis. All animal care and handling procedures were approved by the Institutional Animal Use and Care Committee 
of The Affiliated Huaian No. 1 People's Hospital of Nanjing Medical University.

\section{Statistical analysis}

All data were shown as mean \pm standard deviation (SD). Data were analyzed using either a one-way ANOVA with Bonferroni's correction for comparison of multiple groups or an independent Student's $t$-test for comparison of two groups, as described in figure legends (GraphPad Prism 6.0 software, San Diego, CA, USA). A value of $p<$ 0.05 was considered to be statistically significant $\left({ }^{*} p<0.05,{ }^{* *} p<0.01\right.$ or $\left.{ }^{* * *} p<0.001\right)$.

\section{Results}

MSK1 and pCREB were upregulated

in uveal melanoma tissues

To determine MSK1 expression level in human uveal melanoma tissues, we performed the qRTPCR analysis and western blotting, respectively. As

A
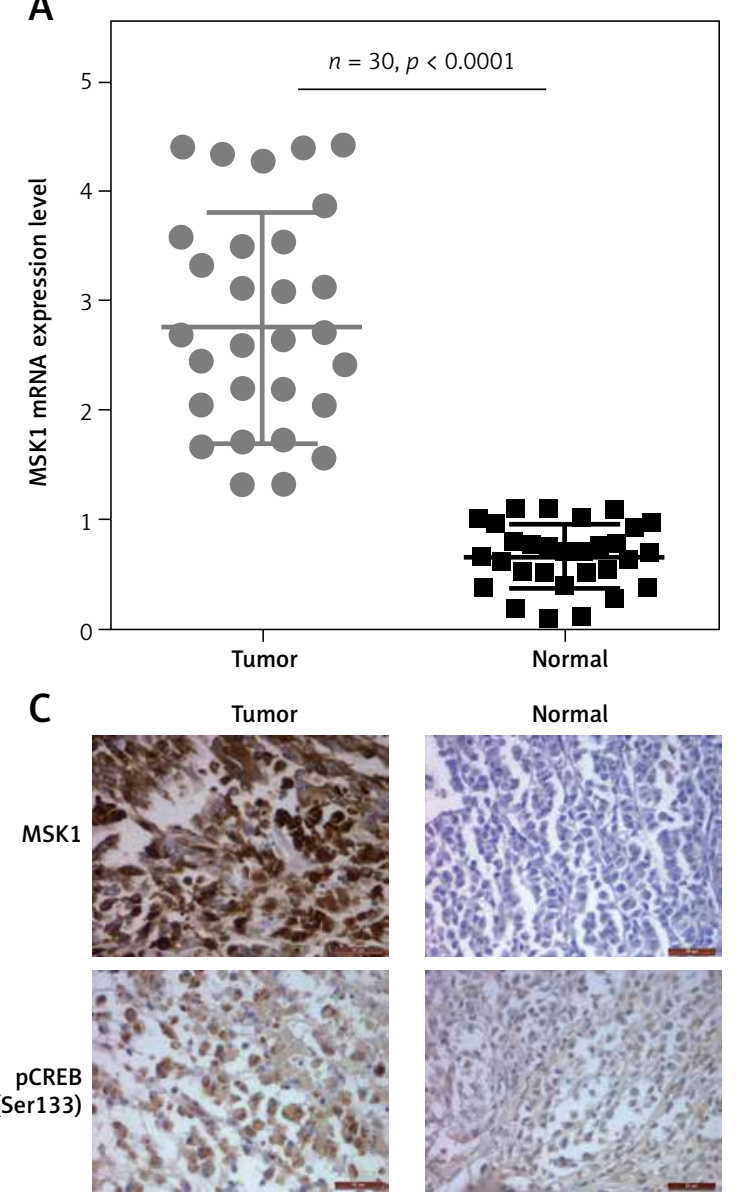

shown in Figure $1 \mathrm{~A}$, our data demonstrated that the MSK1 mRNA expression was strongly up-regulated in human uveal melanoma tissues compared with normal uveal tissues. Western blotting analysis showed that the protein expression of MSK1 and phospho-Ser133-CREB (pCREB) was higher in tumor tissues than that in normal uveal tissues (Figure $1 \mathrm{~B}$ ). Consistently, IHC results demonstrated deeply stained MSK1 and PCREB in tumor tissues, indicating the enhancement of MSK1 and pCREB protein expression in human uveal melanoma tissues (Figure $1 \mathrm{C}$ ). These findings suggested that MSK1 and pCREB probably play a critical role in development of uveal melanoma.

\section{MSK1 facilitates uveal melanoma cell proliferation}

Subsequently, MSK1 was overexpressed or knocked down in uveal melanoma cell lines OCM$1 \mathrm{~A}$ and MUM-2C to explore the role of MSK1 in uveal melanoma cell proliferation. The mRNA and
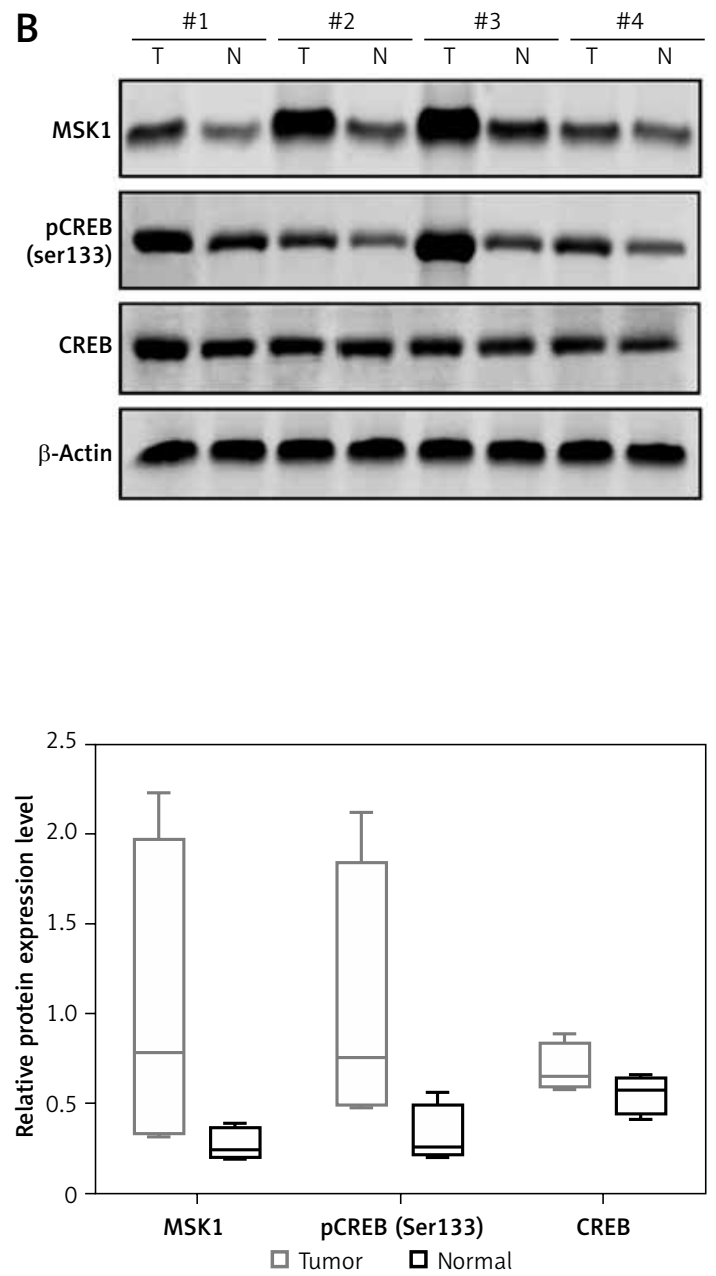

Figure 1. MSK1 and pCREB were upregulated in uveal melanoma tissues. A - Increased mRNA expression level of MSK1 in uveal melanoma tissues compared to normal uveal tissues assayed by qRT-PCR. $N=30, p<0.0001$ for uveal melanoma tissues versus normal uveal tissues. B - Up-regulated MSK1 and pCREB protein level in uveal melanoma tissues. Protein expression was tested by western blotting. $N=4,{ }^{* *} p<0.001$. C $-I H C$ images of MSK1 and $\mathrm{PCREB}$ in human uveal melanoma tissues and normal uveal tissue 
protein expression level of MSK1 in OCM-1A and MUM-2C cell lines confirmed the transfection efficiency (Figures $2 \mathrm{~A}$ and B). Furthermore, we performed MTT assay and colony formation assay to evaluate whether MSK1 was involved in uveal melanoma cell proliferation. Our results showed that cell viability and clone formation of OCM-1A and MUM-2C cells transfected with MSK1-shRNA were suppressed compared to those transfected with the negative control (NC). In contrast, we found that MSK1 overexpression facilitated uveal melanoma cell viability and clone formation (Figures $2 \mathrm{C}$ and D). Additionally, flow cytometric analysis showed that the proportion of OCM-1A and MUM$2 \mathrm{C}$ cells in the G0/G1 phase was remarkably decreased by MSK1 overexpression but increased by MSK1 knockdown (Figure $2 \mathrm{E}$ ). Then, cyclin B1 and cyclin D1, two indicators of cell cycle [30], were assessed and the results suggested that cyclin B1 and cyclin D1 expression levels were elevated with overexpression of MSK1 and decreased by MSK1 knockdown in OCM-1A and MUM-2C cell lines (Figure $2 \mathrm{~F}$ ). These data demonstrated that MSK1 facilitates uveal melanoma cell proliferation.

\section{MSK1 promotes uveal melanoma cell metastasis}

To evaluate the role of MSK1 in uveal melanoma cell migration, we assessed the horizontal and vertical motility abilities of OCM-1A and MUM-2C cells transfected with MSK1 overexpression or knockdown using conventional wound-healing and transwell chamber assays, respectively. We found that uveal melanoma cells transfected with MSK1 overexpression plasmid demonstrated remarkably increased motile and invasive ability. By contrast, downregulation of MSK1 caused completely opposite consequences compared to the control cells (Figures $3 \mathrm{~A}$ and B). Previous studies have shown that matrix metalloproteinase-2 (MMP2) and MMP9 promoted tumor invasion and metastasis by degrading extracellular matrices [31, 32]; thus the protein expression of MMP2 and MMP9 were assessed. The results suggested that MMP2 and MMP9 expression levels were increased by overexpression of MSK1 and decreased by MSK1 knockdown in OCM-1A and MUM-2C cell lines (Figure $3 \mathrm{C})$. These investigations suggested that MSK1 promotes uveal melanoma cell metastasis.

\section{MSK1 mediates activation of CREB by phosphorylation of Ser133 residues}

As previously reported, MSK1 is a nuclear protein that was activated by the ERK $1 / 2$ or $p 38$ MAPK pathways and mediates activation of CREB by phosphorylation of Ser133 residues [11]. To further clarify the molecular mechanism of MSK1 in uveal melanoma progression, we overexpressed or downregulated MSK1 in OCM-1A and MUM$2 \mathrm{C}$ cells, and western blotting was performed to test phosphorylated CREB. We found that overexpression of MSK1 promoted the phosphorylation of CREB and downregulation of MSK1 inhibited pCREB expression in OCM-1A and MUM-2C cell lines (Figure 4 A). Subsequently, we constructed mutant S133A by using site-directed mutagenesis and detected the expression of PCREB and CREB to confirm the mutation effects by western blotting. There was no obvious expression change of CREB $^{\text {Ser133 }}$ compared with the control. Furthermore, we examined the expression level of target genes of MSK1 [14, 33]. Mutation of CREB at Ser133 residues abolished the enhancement of Fos and Jun expression (Figure 4 B). To investigate whether pSer133 of CREB is responsible for MSK1-mediated CREB activation, we co-transfected MSK1 plasmid with CREB $^{\mathrm{Ser} 133}$ mutant plasmid in OCM$1 A$ and MUM-2C cells. We found that upregulation of MSK1 increased expression of pCREB, but this phenomenon was inhibited by mutation of Ser133 residues. Mutation of S133A weakened the impact of MSK1 on CREB phosphorylation (Figure 4 C). This indicated that the Ser133 site of CREB is essential for MSK1-mediated CREB activation.

\section{MSK1 promotes proliferation and metastasis of uveal melanoma cells by phosphorylating CREB}

Furthermore, we co-transfected MSK1 plasmid with $\mathrm{CREB}^{\mathrm{Ser} 133}$ mutant plasmid in OCM-1A and MUM-2C cells and performed the MTT assays and colony formation assay. Our results indicated that cell viability and clone formation of cancer cells were facilitated in cells transfected with MSK1 plasmid alone while this effect was abolished after co-transfecting with $\mathrm{CREB}^{\mathrm{Ser} 133}$ mutant plasmid (Figures $5 \mathrm{~A}$ and $\mathrm{B}$ ). Similarly, the role of MSK1 mediated activation of CREB (pSer133) on uveal melanoma cell metastasis was determined by wound-healing and transwell chamber assays. Uveal melanoma cells with MSK1 overexpression showed obviously increased motile and invasive ability. However, mutation of CREB reversed this consequence (Figures 5 C and D). Thus, MSK1 failed to modulate proliferation and metastasis of uveal melanoma cells as the phosphorylation site at the Ser133 residues was mutated. Our results demonstrated that MSK1 promotes proliferation and metastasis of uveal melanoma cells by phosphorylating CREB.

\section{Inhibition of MSK1 suppresses tumor growth tumor-bearing mice}

Finally, experiments were performed to verify whether inhibition of MSK1 suppressed tu- 
MSK1 promotes cell proliferation and metastasis in uveal melanoma by phosphorylating CREB
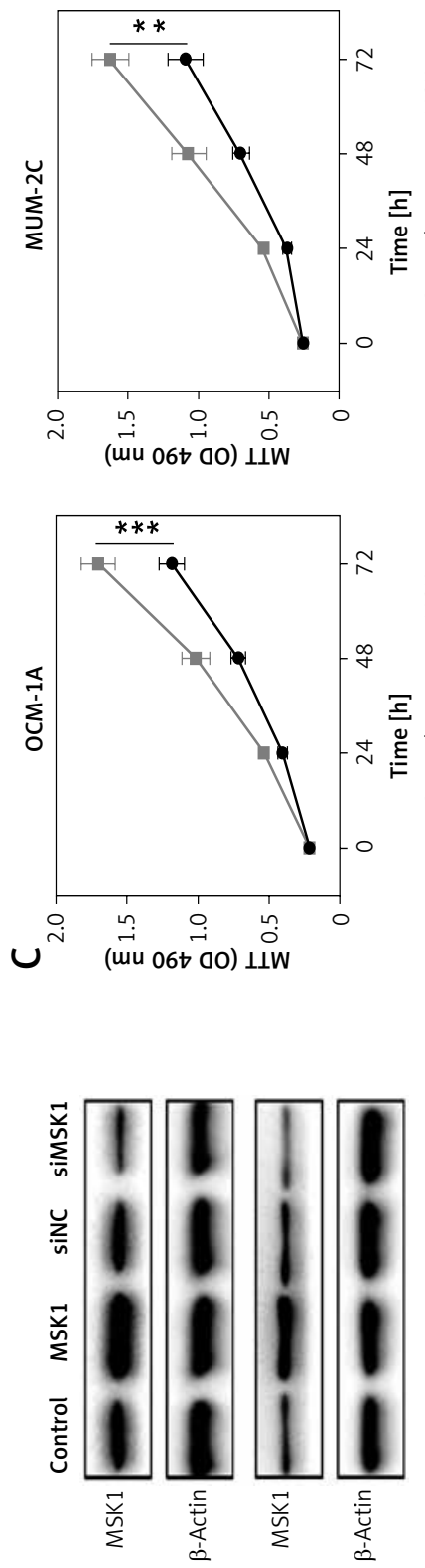

$\infty \quad \forall$ -
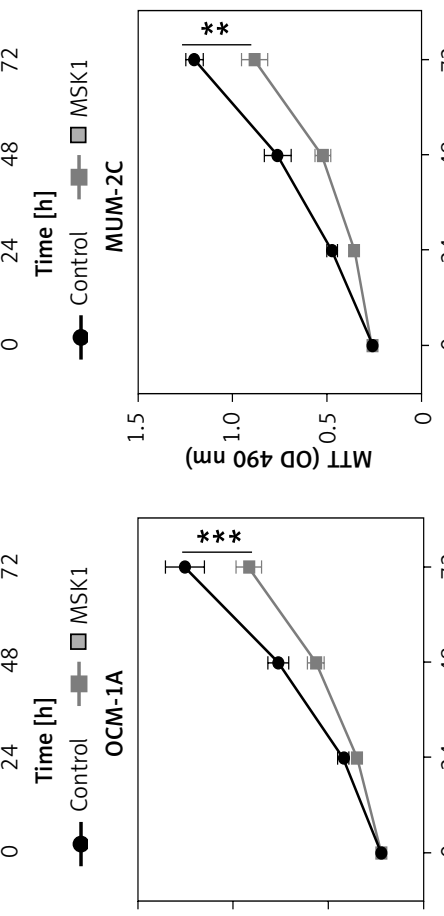
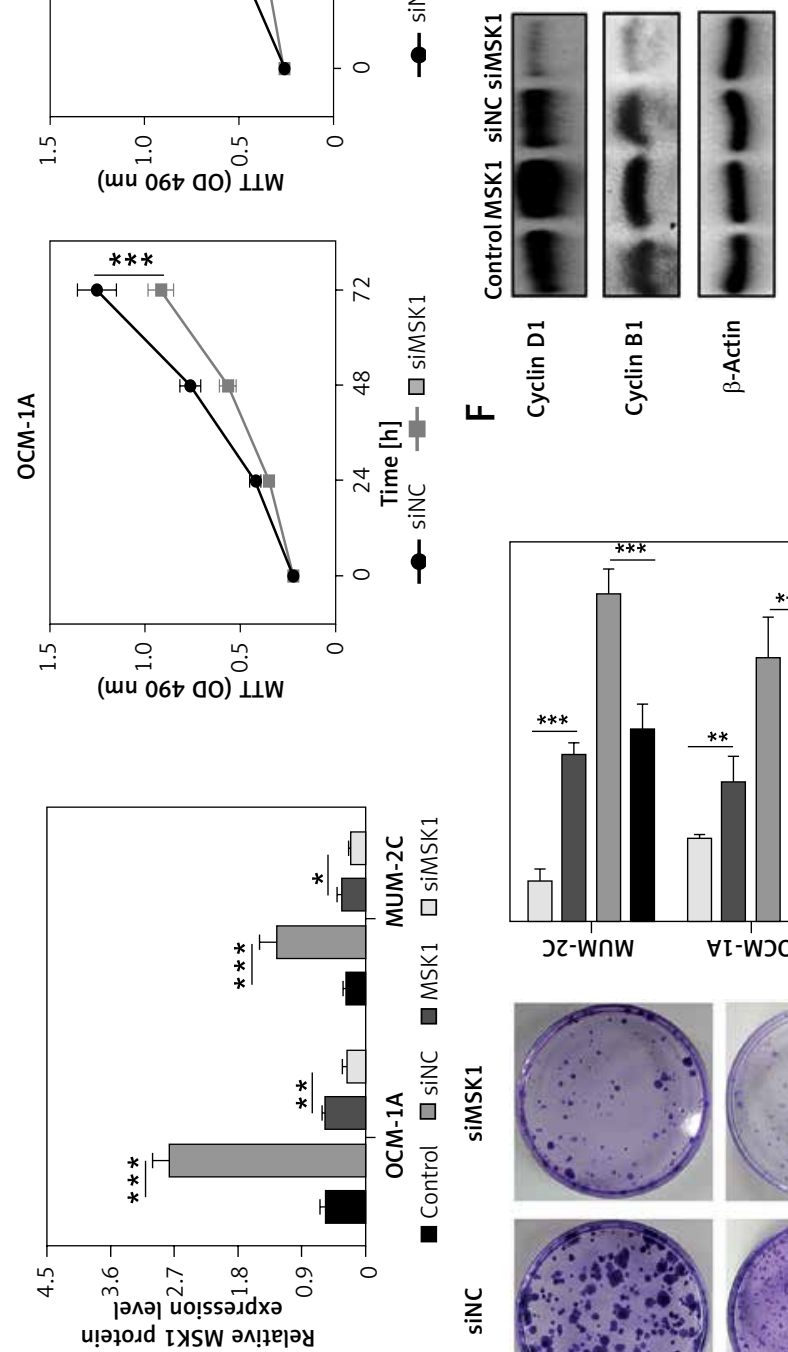

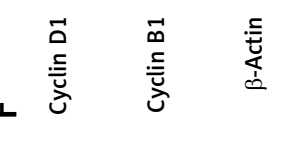

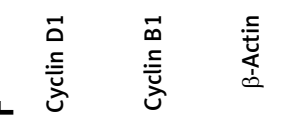

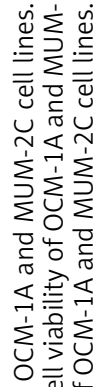

$\circ$

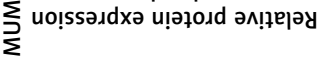

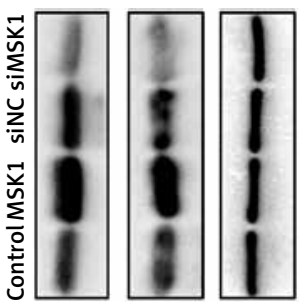

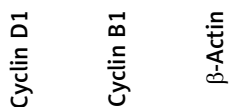

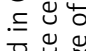

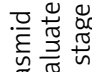

造过

은 훙

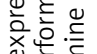

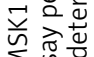

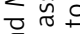

位政

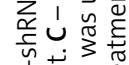

을 $\quad \vec{v}$
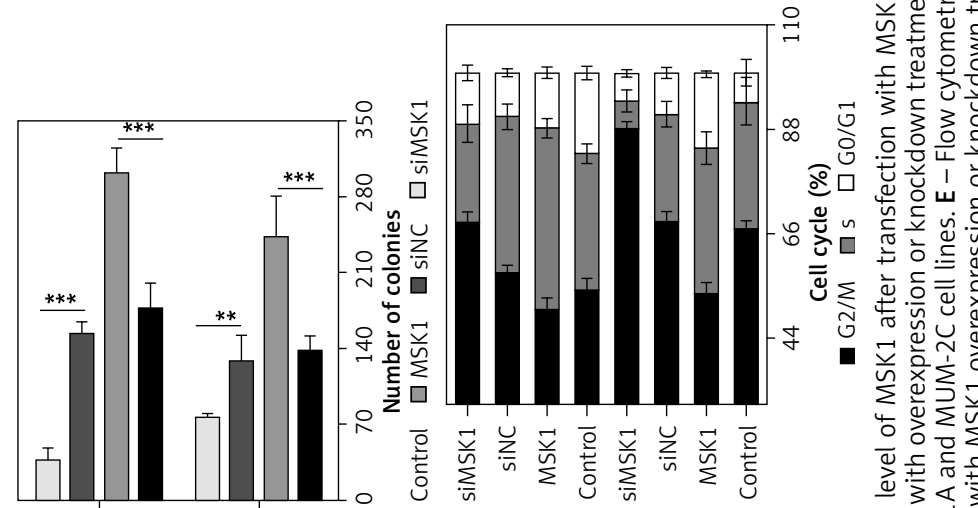

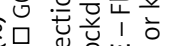

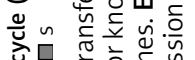

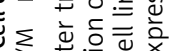

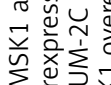

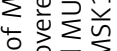

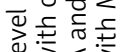
든

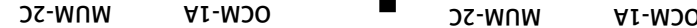

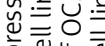
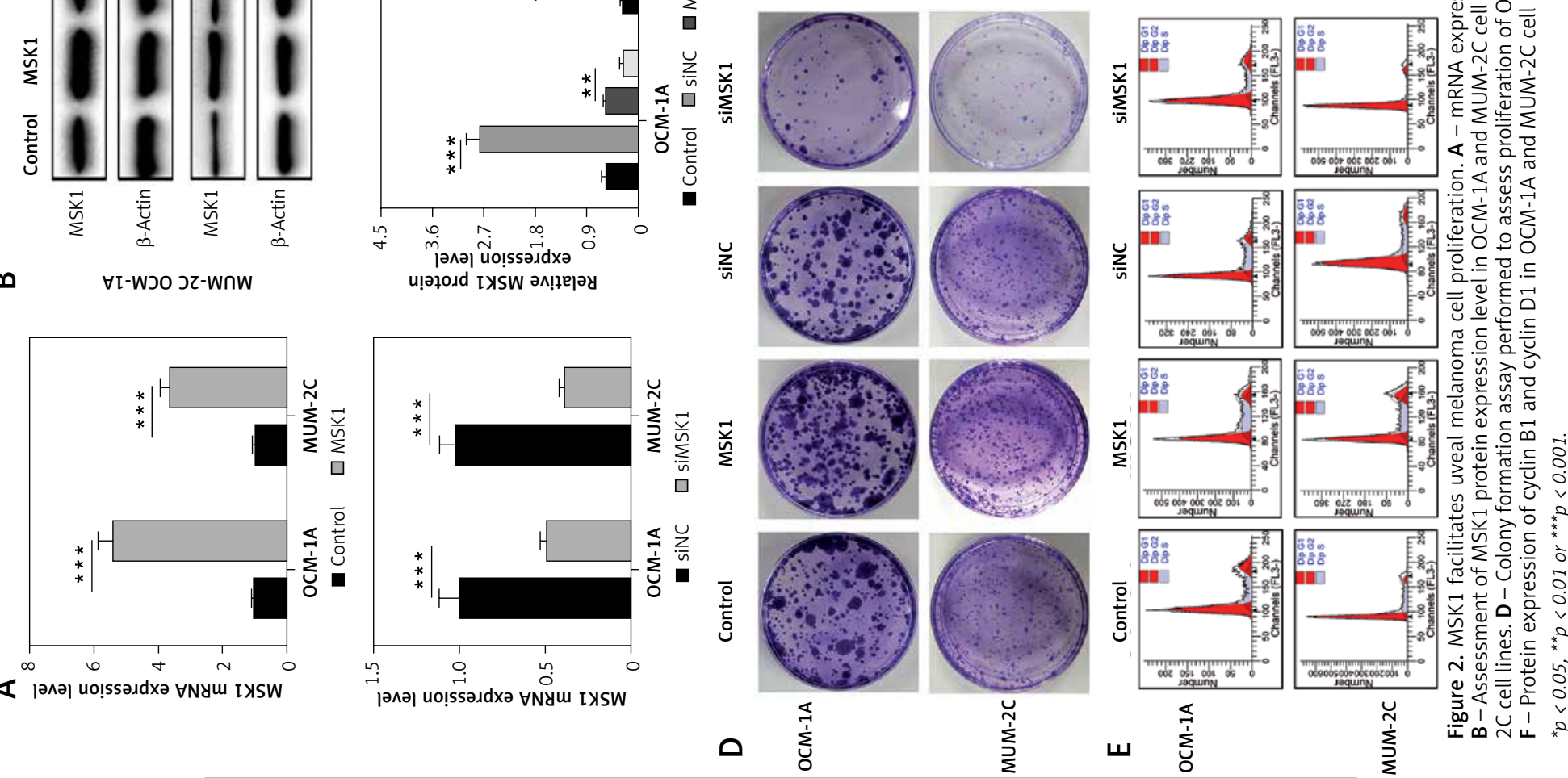

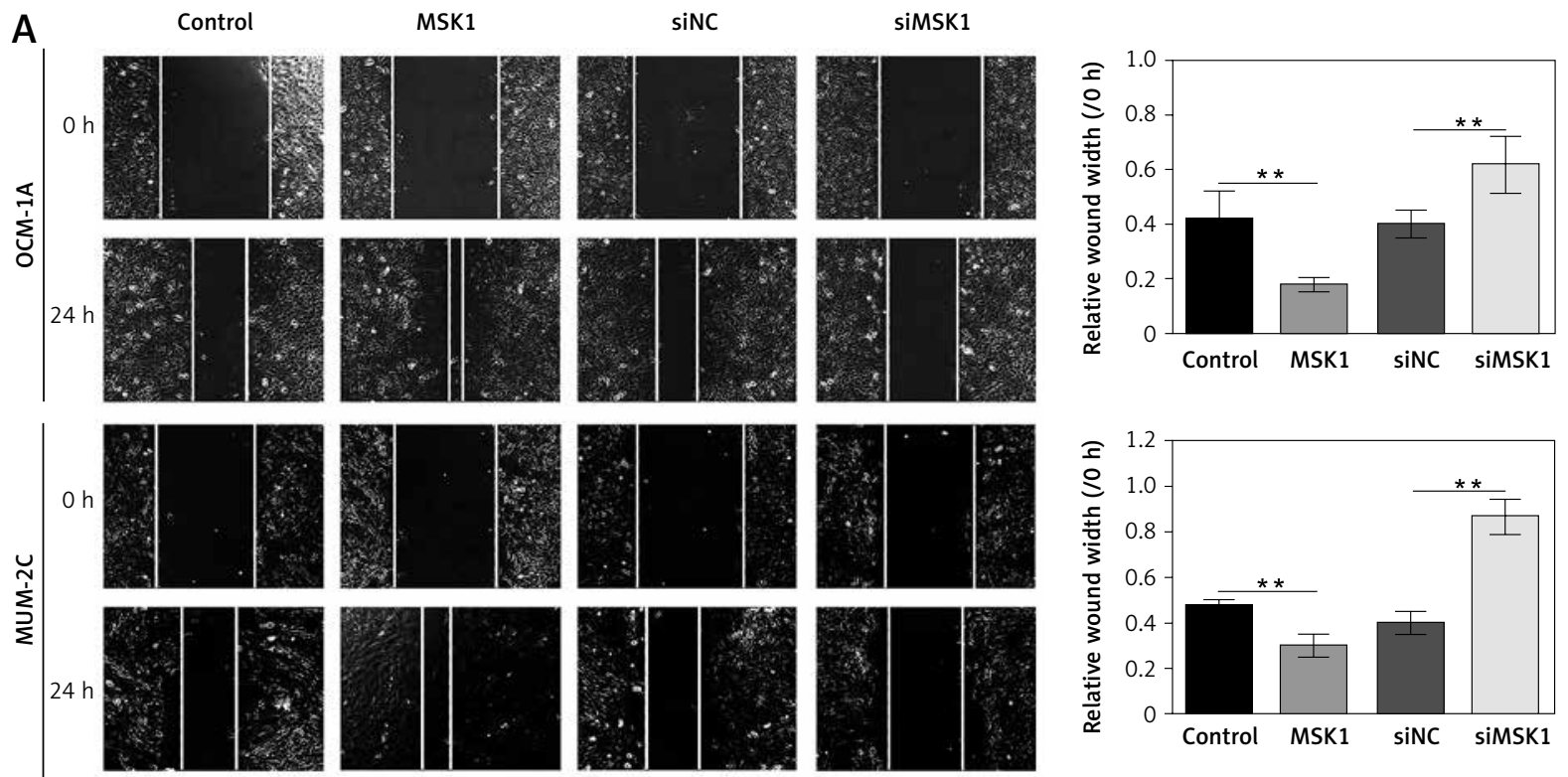

B
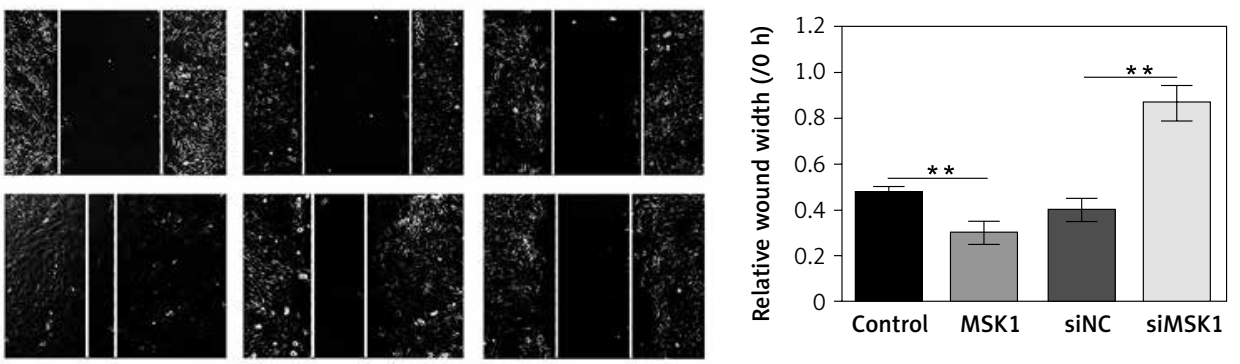

Control

MSK1

$\operatorname{sinC}$

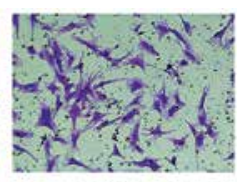

SiMSK1
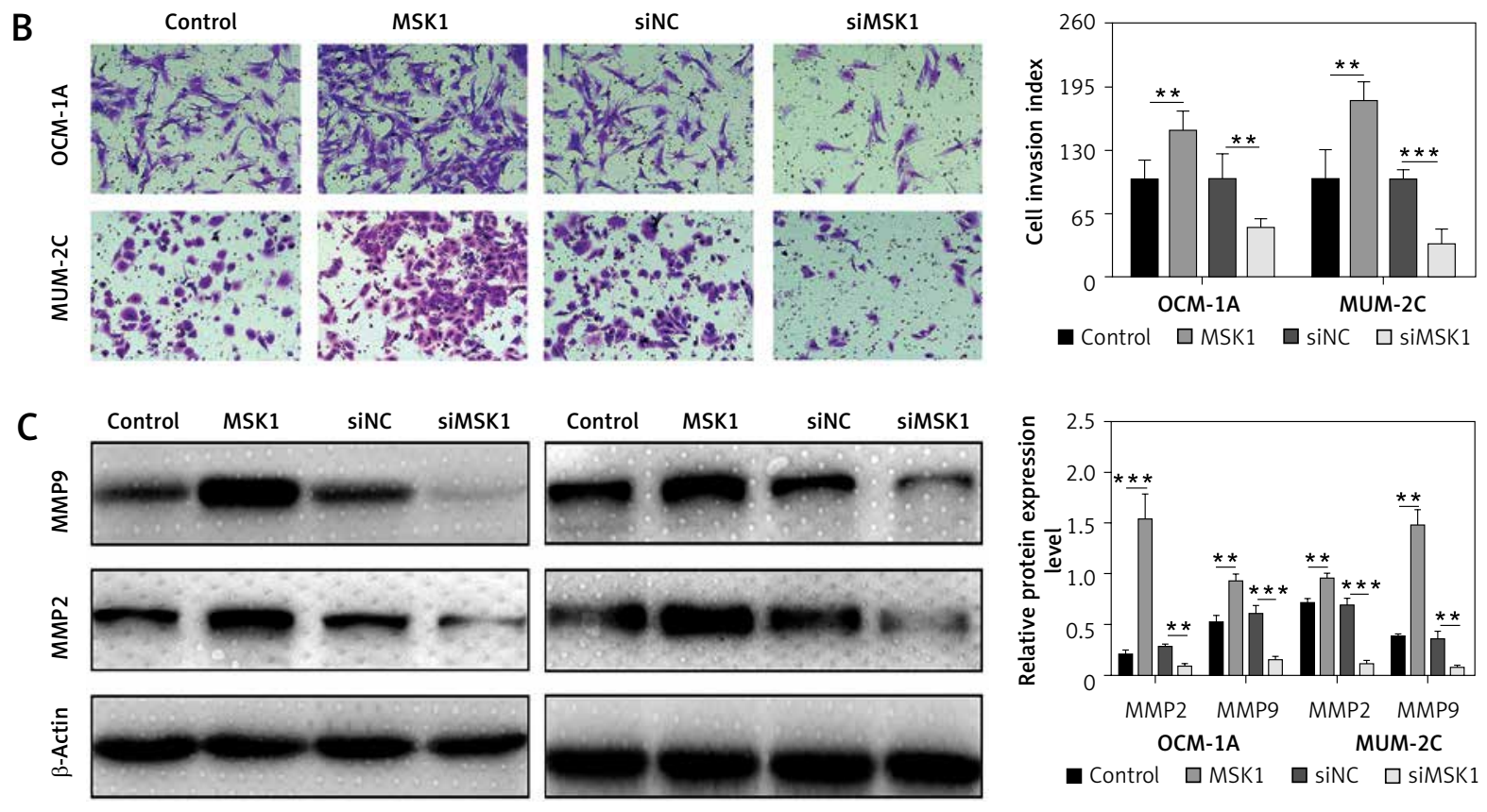

OCM-1A

MUM-2C

Figure 3. MSK1 promotes uveal melanoma cell metastasis. A - Images of wound healing and migration distances at 0 and $24 \mathrm{~h}(100 \times)$. B - Cells invading through the transwell chamber were stained and counted (200x). C - Protein expression of MMP2 and MMP9 in OCM-1A and MUM-2C cell lines with MSK1 overexpression or knockdown treatment

${ }^{*} p<0.05,{ }^{* *} p<0.01$ or ${ }^{* * *} p<0.001$.

mor growth in vivo. Immunodeficient mice were injected with OCM-1A cells stably transfected with MSK1-shRNA (shMSK1) or shNC. Our data demonstrated the tumor weight of the shMSK1 group was lower and the tumor mass grew more slowly than in the shNC group (Figures $6 \mathrm{~A}$ and $B$ ). Results of western blotting suggested that expression of phospho-CREB (Ser133) was downregulated in uveal melanoma tissues of the shMSK1 group (Figure $6 \mathrm{C}$ ). Moreover, the results of $\mathrm{IHC}$ displayed slightly stained MSK1, pCREB and Ki67 in the shMSK1 group, which suggested decreased MSK1, pCREB and Ki67 protein expression in uveal melanoma tissues of the shMSK1 group (Figure $6 \mathrm{D}$ ). Taken together, these results indicate that inhibition of MSK1 suppressed tumor growth in vivo and substantiate our findings that MSK1 promotes proliferation and metastasis of uveal melanoma cell by phosphorylating CREB. 
A

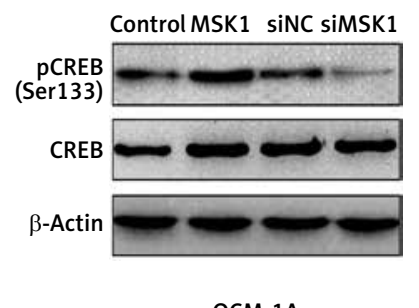

OCM-1A
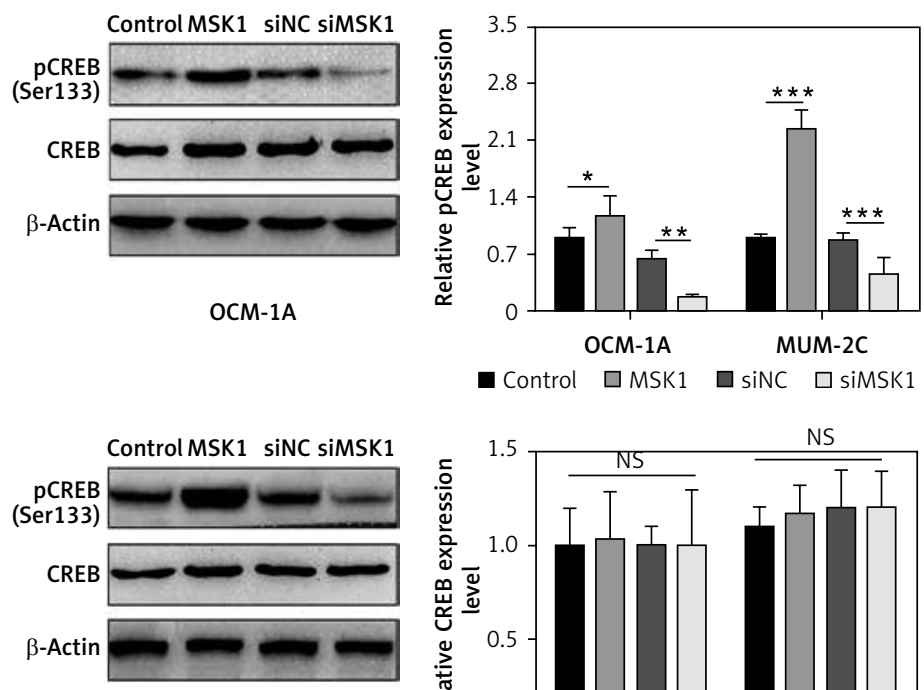

MUM-2C

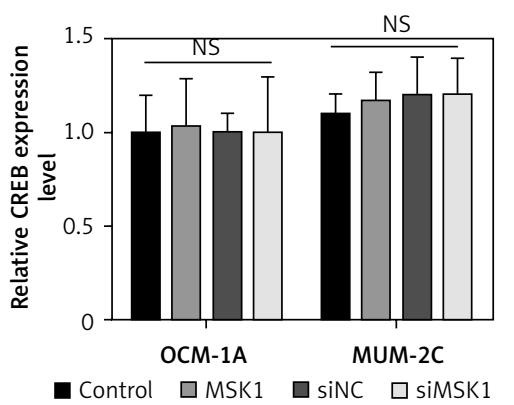

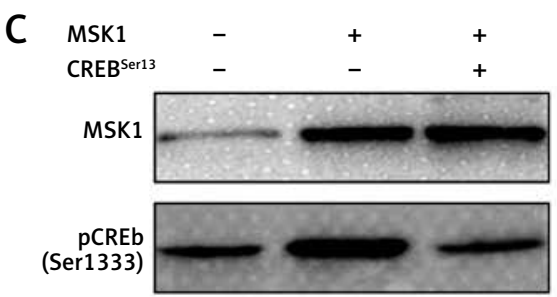

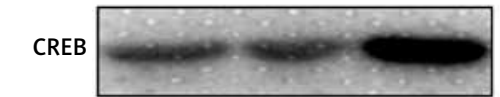

$\beta$-Actin
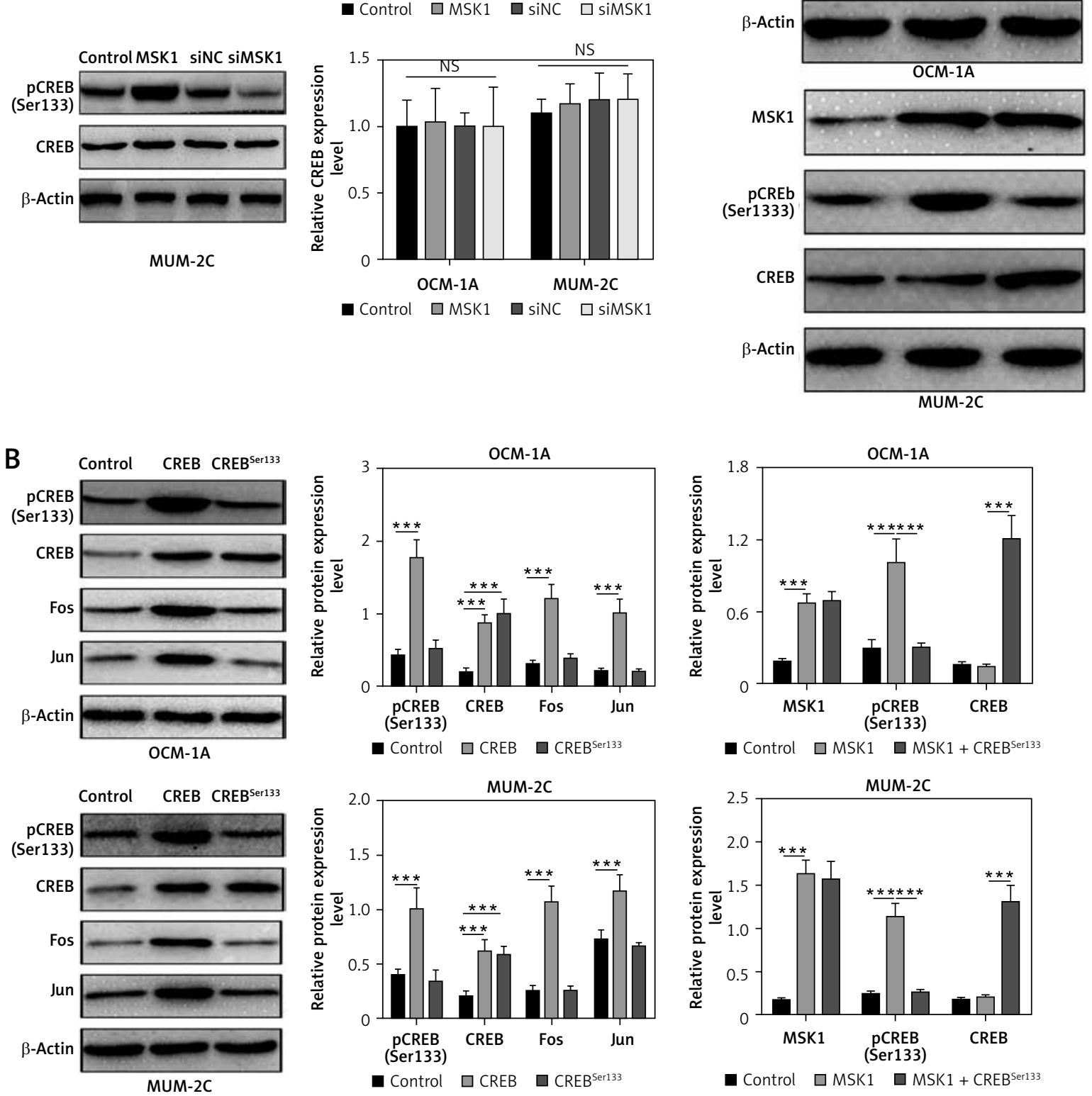

Figure 4. MSK1 activates CREB by phosphorylation at Ser133 residues. A - Protein expression of CREB and pCREB in OCM-1A and MUM-2C cells with MSK1 overexpression or knockdown treatment. B - Protein expression of CREB, pCREB, Fos and Jun in OCM-1A and MUM-2C cells transfected with CREB plasmid or CREB ${ }^{\text {Ser133 }}$ mutant plasmid. C - Protein expression of MSK1, CREB and pCREB in OCM-1A and MUM-2C cells transfected with MSK1 plasmid alone, or together with $\mathrm{CREB}^{\mathrm{Ser} 133}$ mutant plasmid

${ }^{*} p<0.05,{ }^{* *} p<0.01$ or ${ }^{* * *} p<0.001$. 

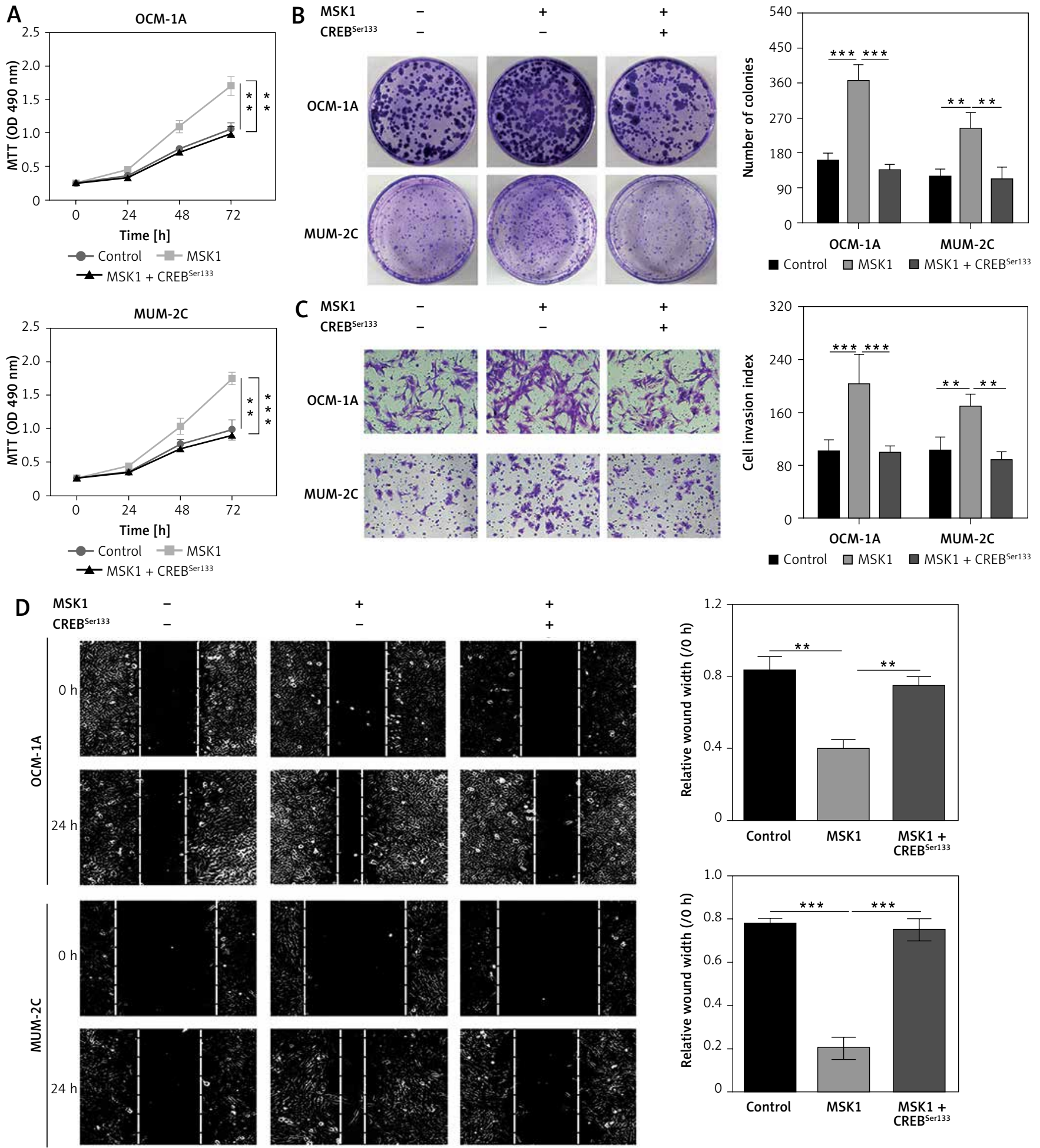

Figure 5. MSK1 promotes proliferation and metastasis of uveal melanoma cells by phosphorylating CREB. A - MTT assay performed to evaluate proliferation of OCM-1A and MUM-2C cells transfected with MSK1 plasmid alone, or together with CREB ${ }^{\text {Ser133 }}$ mutant plasmid. B - Colony formation assay performed to assess proliferation of OCM-1A and $\mathrm{MUM}-2 \mathrm{C}$ cell lines with various treatments. $\mathrm{C}-$ Cells invading through the transwell chamber were stained and counted (200x). D - Images of wound healing and migration distances at 0 and $24 \mathrm{~h}(100 \mathrm{x})$

${ }^{*} p<0.05,{ }^{* *} p<0.01$ or $^{* * *} p<0.001$. 


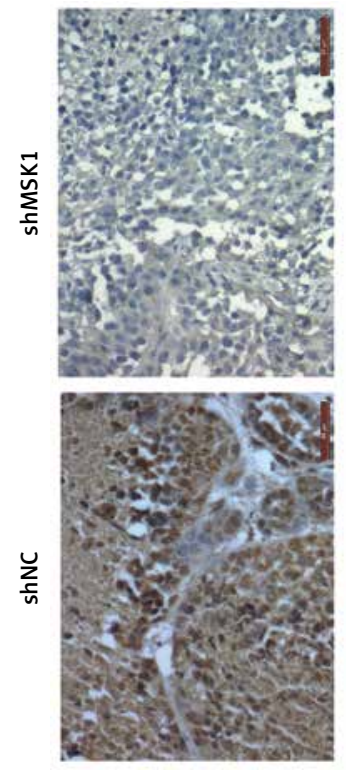

訔

○

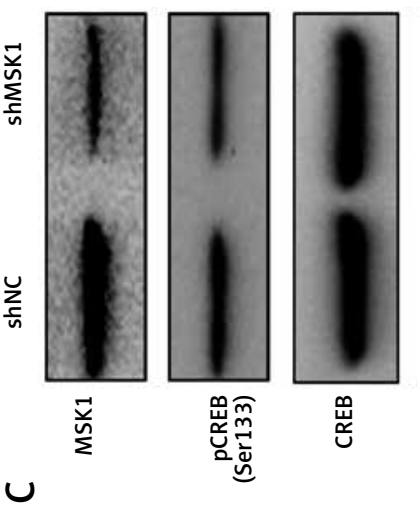

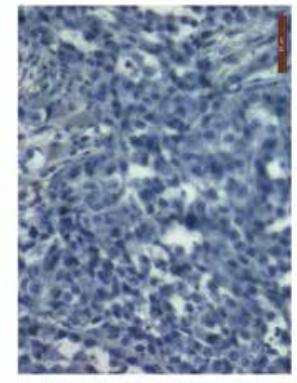

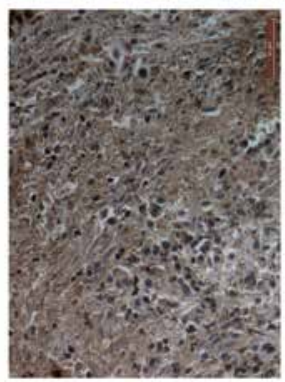

$\stackrel{\frac{\hat{q}}{2}}{2}$

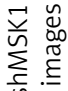

它茎

प!

है

잉

竞

$1 \frac{1}{1}$

웅

ำ

$\bigcup^{0} \underbrace{*}$

只

政

ㅎํㅇำ

$\overline{\overline{0}} \mathrm{z}$

这兵

$\sum_{0}^{1} \frac{0}{ \pm}$

눙 둔

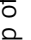

응 임

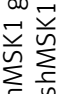

$\sum_{n}$

ज

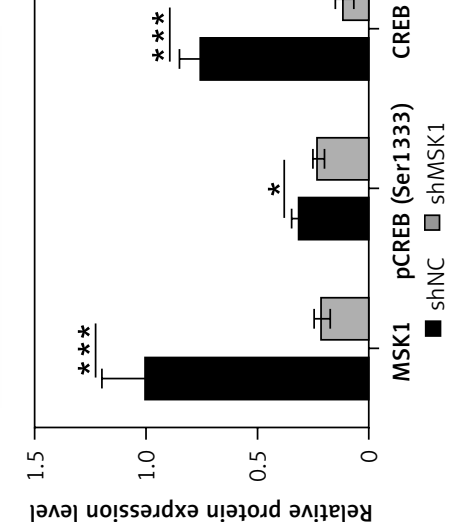

늠

\远

흐

㟧

桴

$\stackrel{\cup}{\sum} \sum^{n} \frac{a}{0}$

ह $\sum_{4}{ }^{4}$

을 은

$\breve{্} \stackrel{\breve{v}}{\vec{v}}$

这文就

$\subseteq \frac{\infty}{\omega}$

華苍苍

品出

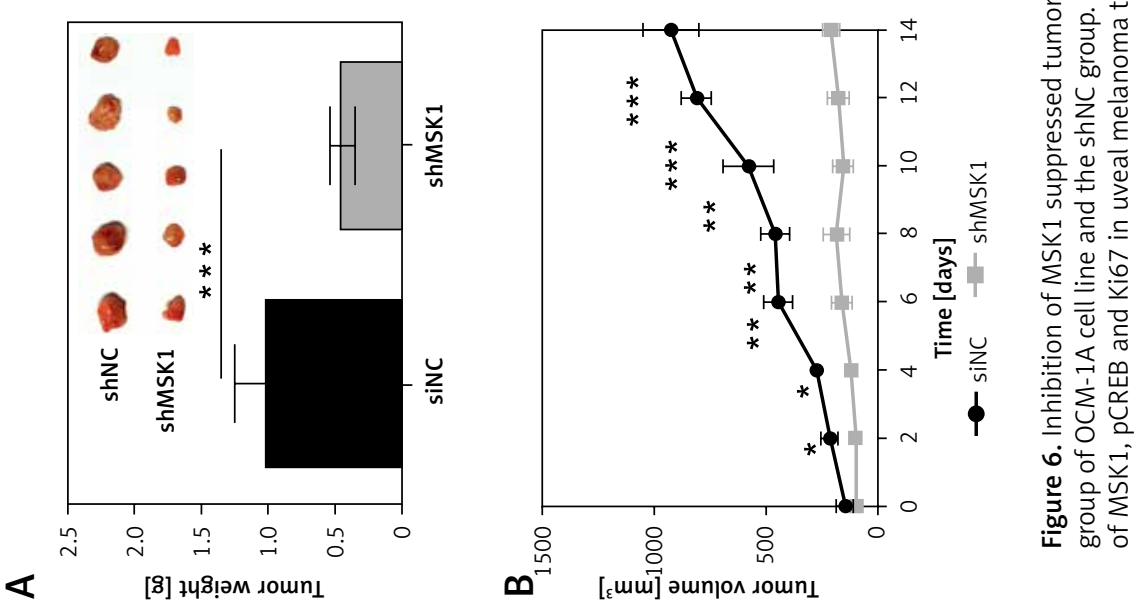




\section{Discussion}

Uveal melanoma is known as a frequent intraocular tumor with high metastasis and poor prognosis. [1]. Progression of uveal melanoma is regulated by lots of potentially interesting genes involved in melanogenesis, cell cycle, apoptosis, the MAPK signal pathway, and the P53 pathway [34]. Interestingly, in our study, we found that MSK1 expression was remarkably elevated in uveal melanoma tissues. This suggests that MSK1 overexpression contributes to the malignant phenotype in uveal melanoma. We then explored the role of MSK1 in uveal melanoma by overexpression and knockdown strategies in OCM-1A and MUM-2C cell lines. Our data suggested that MSK1 facilitated uveal melanoma cell proliferation by increasing cell viability, enhancing clone formation and caused a decreased cell population in G0/G1 phase, and MSK1 also promoted uveal melanoma cell metastasis in consideration of lifting motile and invasive ability. Further studies demonstrated that MSK1 mediates activation of CREB by phosphorylating at Ser133 residues, which thus accelerates the progression of uveal melanoma. Finally, we found that inhibition of MSK1 suppressed tumor growth in BALB/c nude mice.

MSK1 is predominantly localized to the nucleus and plays a critical role in several physiological processes, including inflammation, neuronal plasticity, and function such as memory formation, learning, and responses to external stimuli [14, $35,36]$. It is reported to be implicated in several diseases including Huntington, psoriasis and progression of several tumors [24, 37, 38]. Additionally, $30 \%$ of human cancers are associated with abnormal RAS-MAPK signaling and probably related to elevated MSK1 activity [39]. Previous studies have shown that MSK1 is essential for proliferation of breast cancer cells [15] and malignant phenotype of Ciras-3 cells [17]. Overexpression of MSK1 aggravated tumor aggression and poor prognosis in colorectal cancer [18]. MSK 1 was also implicated in gastric cancer [19] and skin tumor development [20]. These studies suggest that MSK1 plays a crucial role in tumor progression via regulating proliferation and metastasis of cancer cells. We also confirmed that MSK1 accelerates tumor progression by promoting proliferation and metastasis of uveal melanoma cells.

CREB is a transcription factor which exerts its effect on transcription via interaction with cyclic AMP-responsive elements (CREs) in gene promoters $[40,41]$. CREB was activated by MSK1 via phosphorylation at Ser133. [42, 43]. Mutation of the Ser133 site to alanine in the endogenous CREB gene exerts a significant impact on CREB target genes in response to MSK1 activating stimuli [23, 44]. Several studies have highlighted the important role of CREB in tumor progression and impli- cated its role in acute myeloid leukemia [45], acute lymphoblastic leukemia [46, 47], myelomonocytic leukemia [48], Hodgkin lymphoma [49] and nonsmall cell lung cancer $[50,51]$. Here, we also found the upregulation of $p$-CREB in uveal melanoma tissues, indicating its role in tumor progression. Particularly, emerging evidence suggests that the regulatory effect of MSK1 mediated by CREB phosphorylation has been related to various biological processes such as melanogenesis in human melanocytes [26], cytokine production in human neutrophils [27], and the TNF signal pathway [28]. Consistently, this underlying mechanism was also verified in our study. Our data indicated that MSK1 mediates activation of CREB by phosphorylation of Ser133 residues and promotes proliferation and metastasis of uveal melanoma cells. However, the detailed molecular mechanism involved in the regulatory effects of MSK1 on CREB is unclear. Thus, further exploration is required to solve this puzzle.

Considering the fact that MSK1 is activated by ERK $1 / 2$ or p38 MAPK pathways and can regulate the expression of its downstream target CREB, it is might be an effective linkage between the upstream signaling cascade and the downstream targets such as CREB [23]. It is also a promising candidate for uveal melanoma therapy and especially has a tremendous potential role in treatment of cancers in which the MSK1-CREB pathway is abnormally active. Moreover, as knockout mice of MSK1 are viable and fertile [20, 52], deficiency of MSK1 activity probably had no significant negative impact on normal tissue cells.

In conclusion, this study indicated that MSK1 promotes proliferation and metastasis of uveal melanoma cells by phosphorylated CREB at Ser133 residues. Our findings suggested that targeting MSK1 might be a potential strategy for uveal melanoma treatment.

\section{Conflict of interest}

The authors declare no conflict of interest.

\section{References}

1. Krantz BA, Dave N, Komatsubara KM, Marr BP, Carvajal RD. Uveal melanoma: epidemiology, etiology, and treatment of primary disease. Clin Ophthalmol 2017; 11: 279-89.

2. Kaliki S, Shields CL. Uveal melanoma: relatively rare but deadly cancer. Eye (Lond) 2017; 31: 241-57.

3. Brasiuniene B, Sokolovas V, Brasiunas V, Barakauskiene A, Strupas K. Combined treatment of uveal melanoma liver metastases. Eur J Med Res 2011; 16: 71-5.

4. Salmon RJ, Levy C, Plancher C, et al. Treatment of liver metastases from uveal melanoma by combined surgery-chemotherapy. Eur J Surg Oncol 1998; 24: 127-30.

5. Chattopadhyay C, Kim DW, Gombos DS, et al. Uveal melanoma: from diagnosis to treatment and the science in between. Cancer 2016; 122: 2299-312. 
6. Buder K, Gesierich A, Gelbrich G, Goebeler M. Systemic treatment of metastatic uveal melanoma: review of literature and future perspectives. Cancer Med 2013; 2: 674-86.

7. Yousef YA, Alkilany M. Characterization, treatment, and outcome of uveal melanoma in the first two years of life. Hematol Oncol Stem Cell Ther 2015; 8: 1-5.

8. Sagus M, Bedikian AY. Uveal melanoma in the first 4 decades of life. South Med J 2015; 108: 158-63.

9. Patel SP. Latest developments in the biology and management of uveal melanoma. Curr Oncol Rep 2013; 15 509-16.

10. Pierrat B, Correia JS, Mary JL, Tomas-Zuber M, Lesslauer W. RSK-B, a novel ribosomal S6 kinase family member, is a CREB kinase under dominant control of p38alpha mitogen-activated protein kinase (p38alphaMAPK). J Biol Chem 1998; 273: 29661-71.

11. Deak M, Clifton AD, Lucocq LM, Alessi DR. Mitogen- and stress-activated protein kinase-1 (MSK1) is directly activated by MAPK and SAPK2/p38, and may mediate activation of CREB. Embo J 1998; 17: 4426-41.

12. New L, Jiang $Y$, Zhao $M$, et al. PRAK, a novel protein kinase regulated by the p38 MAP kinase. Embo J 1998; 17: 3372-84.

13. Funding AT, Johansen C, Kragballe K, et al. Mitogen- and stress-activated protein kinase 1 is activated in lesional psoriatic epidermis and regulates the expression of pro-inflammatory cytokines. J Invest Dermatol 2006. 126: 1784-91.

14. Reyskens KM, Arthur JS. Emerging roles of the mitogen and stress activated kinases MSK 1 and MSK2. Front Cell Dev Biol 2016; 4: 56.

15. Reyes D, Ballare C, Castellano G, et al. Activation of mitogen- and stress-activated kinase 1 is required for proliferation of breast cancer cells in response to estrogens or progestins. Oncogene 2014; 33: 1570-80.

16. Pu X, Storr SJ, Ahmad NS, et al. High nuclear MSK1 is associated with longer survival in breast cancer patients. 2018; 144: 509-17.

17. Perez-Cadahia B, Drobic B, Espino PS, et al. Role of MSK1 in the malignant phenotype of Ras-transformed mouse fibroblasts. J Biol Chem 2011; 286: 42-9.

18. Fu X, Fan X, Hu J, et al. Overexpression of MSK1 is associated with tumor aggressiveness and poor prognosis in colorectal cancer. Dig Liver Dis 2017; 49: 683-91.

19. Khan SA, Amnekar R, Khade B, et al. p38-MAPK/MSK1mediated overexpression of histone $\mathrm{H} 3$ serine 10 phosphorylation defines distance-dependent prognostic value of negative resection margin in gastric cancer. Clin Epigenetics 2016; 8: 88.

20. Chang S, Iversen L, Kragballe K, Arthur JS, Johansen C. Mice lacking MSK1 and MSK2 show reduced skin tumor development in a two-stage chemical carcinogenesis model. Cancer Invest 2011; 29: 240-5.

21. Roux PP, Blenis J. ERK and p38 MAPK-activated protein kinases: a family of protein kinases with diverse biological functions. Microbiol Mol Biol Rev 2004; 68: 320-44.

22. Kefaloyianni E, Gaitanaki C, Beis I. ERK $1 / 2$ and p38MAPK signalling pathways, through MSK1, are involved in NF-kappaB transactivation during oxidative stress in skeletal myoblasts. Cell Signal 2006; 18: 2238-51.

23. Naqvi S, Martin KJ, Arthur JS. CREB phosphorylation at Ser133 regulates transcription via distinct mechanisms downstream of CAMP and MAPK signalling. Biochem J 2014; 458: 469-79.

24. Kim HG, Lee KW, Cho YY, et al. Mitogen- and stress-activated kinase 1-mediated histone $\mathrm{H} 3$ phosphorylation is crucial for cell transformation. Cancer Res 2008; 68: 2538-47.

25. Arthur JS, Cohen P. MSK1 is required for CREB phosphorylation in response to mitogens in mouse embryonic stem cells. FEBS Lett 2000; 482: 44-8.

26. Niwano T, Terazawa S, Nakajima H, Imokawa G. The stem cell factor-stimulated melanogenesis in human melanocytes can be abrogated by interrupting the phosphorylation of MSK1: evidence for involvement of the p38/MSK1/CREB/MITF axis. 2018; 310: 187-96.

27. Mayer TZ, Simard FA, Cloutier A, Vardhan H, Dubois CM, McDonald PP. The p38-MSK1 signaling cascade influences cytokine production through CREB and C/EBP factors in human neutrophils. J Immunol 2013; 191: 4299-307.

28. Gustin JA, Pincheira R, Mayo LD, et al. Tumor necrosis factor activates CRE-binding protein through a p38 MAPK/MSK1 signaling pathway in endothelial cells. Am J Physiol Cell Physiol 2004; 286: C547-55.

29. Simmons ML, Lamborn KR, Takahashi M, et al. Analysis of complex relationships between age, p53, epidermal growth factor receptor, and survival in glioblastoma patients. Cancer Res 2001; 61: 1122-8.

30. Zhao M, Kim YT, Yoon BS, et al. Expression profiling of cyclin B1 and D1 in cervical carcinoma. Exp Oncol 2006; 28: 44-8.

31. Li H, Qiu Z, Li F, Wang C. The relationship between MMP2 and MMP-9 expression levels with breast cancer incidence and prognosis. Oncol Lett 2017; 14: 5865-70.

32. Alsayad FA. The role of matrix metalloproteinases in cancer progression, in particular metastasis. Arch Med Sci Civil Dis 2018; 3: 124-6.

33. Fallahi M, Amelio AL, Cleveland JL, Rounbehler RJ. CREB targets define the gene expression signature of malignancies having reduced levels of the tumor suppressor tristetraprolin. PLoS One 2014; 9: e115517.

34. An J, Wan H, Zhou X, et al. A comparative transcriptomic analysis of uveal melanoma and normal uveal melanocyte. PLoS One 2011; 6: e16516.

35. Adewumi I, Lopez C, Davie JR. Mitogen and stress-activated protein kinase regulated gene expression in cancer cells. Adv Biol Regul 2019; 71: 147-55.

36. Brami-Cherrier K, Roze E, Girault JA, Betuing S, Caboche J. Role of the ERK/MSK1 signalling pathway in chromatin remodelling and brain responses to drugs of abuse. J Neurochem 2009; 108: 1323-35.

37. Francelle L, Galvan L, Brouillet E. Possible involvement of self-defense mechanisms in the preferential vulnerability of the striatum in Huntington's disease. Front Cell Neurosci 2014; 8: 295.

38. Gesser B, Johansen C, Rasmussen MK, et al. Dimethylfumarate specifically inhibits the mitogen and stress-activated kinases 1 and 2 (MSK1/2): possible role for its anti-psoriatic effect. J Invest Dermatol 2007; 127: 2129-37.

39. Dunn KL, Espino PS, Drobic B, He S, Davie JR. The RasMAPK signal transduction pathway, cancer and chromatin remodeling. Biochem Cell Biol 2005; 83: 1-14.

40. Silva AJ, Kogan JH, Frankland PW, Kida S. CREB and memory. Annu Rev Neurosci 1998; 21: 127-48.

41. Wen AY, Sakamoto KM, Miller LS. The role of the transcription factor CREB in immune function. J Immunol 2010; 185: 6413-9.

42. Davie JR. MSK1 and MSK2 mediate mitogen- and stress-induced phosphorylation of histone $\mathrm{H} 3$ : a controversy resolved. Sci STKE 2003; 2003: Pe33.

43. Healy S, Khan P, He S, Davie JR. Histone H3 phosphorylation, immediate-early gene expression, and the nucle- 
osomal response: a historical perspective. Biochem Cell Biol 2012; 90: 39-54.

44. Shi GX, Cai W, Andres DA. Rit-mediated stress resistance involves a p38-mitogen- and stress-activated protein kinase 1 (MSK1)-dependent CAMP response element-binding protein (CREB) activation cascade. J Biol Chem 2012; 287: 39859-68.

45. Shankar DB, Cheng JC, Kinjo K, et al. The role of CREB as a proto-oncogene in hematopoiesis and in acute myeloid leukemia. Cancer Cell 2005; 7: 351-62.

46. van der Sligte NE, Kampen KR, ter Elst A, et al. Essential role for cyclic-AMP responsive element binding protein 1 (CREB) in the survival of acute lymphoblastic leukemia. Oncotarget 2015; 6: 14970-81.

47. Shabestari RM, Safa M, Alikarami F, Banan M, Kazemi A. CREB knockdown inhibits growth and induces apoptosis in human pre-B acute lymphoblastic leukemia cells through inhibition of prosurvival signals. Biomed Pharmacother 2017; 87: 274-9.

48. Liu YL, Lensing SY, Yan Y, Cooper TM, Loh ML, Emanuel PD. Deficiency of CREB and over expression of miR-183 in juvenile myelomonocytic leukemia. Leukemia 2013; 27: 1585-8.

49. Lu F, Zheng Y, Donkor PO, Zou P, Mu P. Downregulation of CREB promotes cell proliferation by mediating $\mathrm{G} 1 / \mathrm{S}$ phase transition in Hodgkin lymphoma. Oncol Res 2016; 24: 171-9.

50. Seo HS, Liu DD, Bekele BN, et al. Cyclic AMP response element-binding protein overexpression: a feature associated with negative prognosis in never smokers with nonsmall cell lung cancer. Cancer Res 2008; 68: 6065-73.

51. Aggarwal S, Kim SW, Ryu SH, Chung WC, Koo JS. Growth suppression of lung cancer cells by targeting cyclic AMP response element-binding protein. Cancer Res 2008; 68: 981-8.

52. MacKenzie KF, Van Den Bosch MW, Naqvi S, et al. MSK1 and MSK2 inhibit lipopolysaccharide-induced prostaglandin production via an interleukin-10 feedback loop. Mol Cell Biol 2013; 33: 1456-67. 